Use of ${ }^{111}$ In-DTPA-octreotide scintigraphy in the diagnosis of neuroendocrine and non-neuroendocrine tumors of the lung. Preliminary results. J Cardiovasc Surg. 1997;38:313-5.

9. Musi M, Carbone RG, Bertocchi C, Cantalupi DP, Pugliese C, Virotta G. Bronchial carcinoid tumors: a study on clinicopathological features and role of octreotide scintigraphy. Lung Cancer. 1998; 22:97-102.
10. Erasmus JJ, McAdams HP, Patz EF Jr, Coleman RE, Ahuja V, Goodman PC. Evaluation of primary pulmonary carcinoid tumors using FDG PET. AJR Am J Roentgenol. 1998;170:1369-73.

11. El Jamal M, Nicholson AG, Goldstraw P. The feasibility of conservative resection for carcinoid tumours: is pneumonectomy even necessary for uncomplicated cases? Eur J Cardiothorac Surg. 2000;18: 301-6.

\title{
An autopsy case of angiosarcoma arising around a woven Dacron prosthesis after a Cabrol operation
}

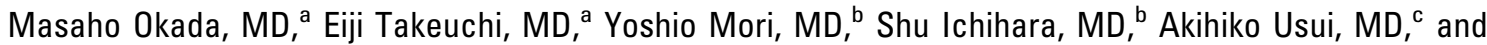 \\ Yuichi Ueda, MD, ${ }^{\mathrm{C}}$ Nagoya, Japan
}

\begin{abstract}
Clinical Summary
A 50-year-old man who was given a diagnosis of Marfan syndrome was hospitalized because of a right visual field defect. $\mathrm{He}$ had undergone a Cabrol operation for annuloaortic ectasia and aortic valve regurgitation 17 years earlier. His ascending aorta and aortic root were replaced with a woven Dacron graft (DeBakey Vasculour; C.R. Bard, Inc, Murray Hill, NJ) and a mechanical valve (Björk-Shiley monostrut heart valve, $25 \mathrm{~mm}$; Shiley, Inc, Irvine, Calif). He underwent mitral valve replacement with a mechanical valve for mitral valve insufficiency caused by acute endocarditis 5 years earlier. He was hospitalized because of rightside hemiparesis but fell into a semicoma thereafter. Computed tomography $(\mathrm{CT})$ revealed a left occipital brain tumorous shadow. A tumorectomy of the left occipital lobe was performed, but the patient died as a result of an expanding brain hemorrhage 2 weeks later. The brain tumor was diagnosed as metastatic angiosarcoma.
\end{abstract}

\section{Autopsy Findings}

The aortic root had a wrap inclusion of the aneurysmal sac surrounding a woven Dacron aortic graft. There was a tumorous mass along the noncoronary cusp of the anastomosed site, with soft granulation tissue in it (Figure 1). The tumor extended into the aneurysmal sac and invaded the graft inside as well. The brain had multiple metastatic tumors and expanding hemorrhaging. There were no metastatic tumors in the other organs.

From the Departments of Cardiovascular Surgery ${ }^{\mathrm{a}}$ and Pathology, ${ }^{\mathrm{b}}$ Nagoya National Hospital, and the Department of Cardiovascular Surgery, ${ }^{\mathrm{c}}$ Nagoya University Graduate School of Medicine, Nagoya, Japan.

Received for publication Nov 1, 2003; revisions requested Dec 24, 2003 accepted for publication Jan 8, 2004.

Address for reprints: Masaho Okada, MD, Department of Cardiovascular Surgery, Nagoya University School of Medicine, 65 tsurumaicho, Shouwaku, Nagoya, Aichi 466-8560, Japan (E-mail: OKMASAHO@aol.com).

J Thorac Cardiovasc Surg 2004;127:1843-5

$0022-5223 / \$ 30.00$

Copyright $\odot 2004$ by The American Association for Thoracic Surgery

doi:10.1016/j.jtcvs.2004.01.021
Microscopic examination revealed a moderately differentiated angiosarcoma arranged in complex anastomosing channels and irregular sheets (Figure 2).

Neoplastic endothelial cells proliferated on the Dacron graft, mainly outside but also inside. Neoplasmic cells were also observed among individual Dacron fibers. There were poorly cohesive neoplasmatic cells in the wrap inclusion of the aneurysmal sac. Among immunohistochemical markers for endothelial differentiation, only CD31 was positive; CD34 and factor VIII were both negative.

\section{Discussion}

Foreign bodies have been shown to induce sarcomas in experimental animals, ${ }^{1}$ but it has only rarely been reported in human subjects that sarcomas have developed adjacent to foreign material introduced into the body either iatrogenically or accidentally. ${ }^{2}$ In thoracic surgery various forms of Dacron prostheses are commonly used. Oppenheimer and colleagues ${ }^{1}$ briefly mentioned that the common denomination of tumor-producing materials was a long-chain polymer structure, such as Dacron. Seven sarcomas have been reported arising in association with Dacron vascular prostheses in the English-language literature. ${ }^{3-6}$ The present case is angiosarcoma arising from the anastomosed site of the aortic root with a Dacron aortic graft. Neoplastic cells strongly expressed CD31, a reliable marker that has both relative specificity and excellent sensitivity to angiosarcomas of all types, ${ }^{7,8}$ confirming the pathologic diagnosis. Neoplastic cells infiltrated both sides of the endothelial layer of the graft from the anastomosed site. Therefore we speculate that the anastomosed site with a Dacron graft is the origin of the angiosarcoma. Angiosarcoma has also been reported to have developed at the site of defunctionalized arteriovenous fistulas. ${ }^{9,10}$ The wrap inclusion of the aneurysmal sac around the aortic root is one example of a defunctionalized arteriovenous fistula. There was a thrombus with neoplastic cells in it. An exuberant host response around the foreign material might represent an important intermediate step in the development of the sarcoma. ${ }^{11}$ The cells in the inflammatory or repair process rarely undergo a malignant transformation, which is probably associated with an oncogene activation and a tumor suppressor gene inacti- 


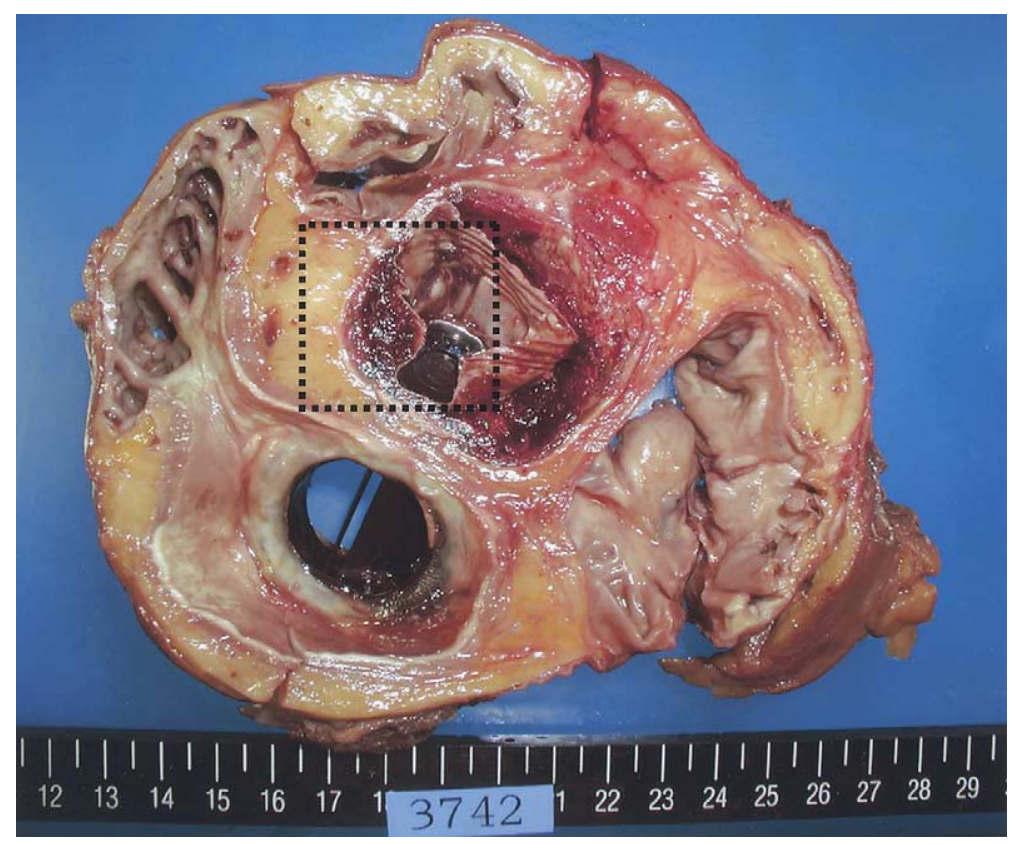

Figure 1. Autopsy finding of a woven Dacron prosthesis of the aortic root after Cabrol operation. The tumor was found in the dotted line.

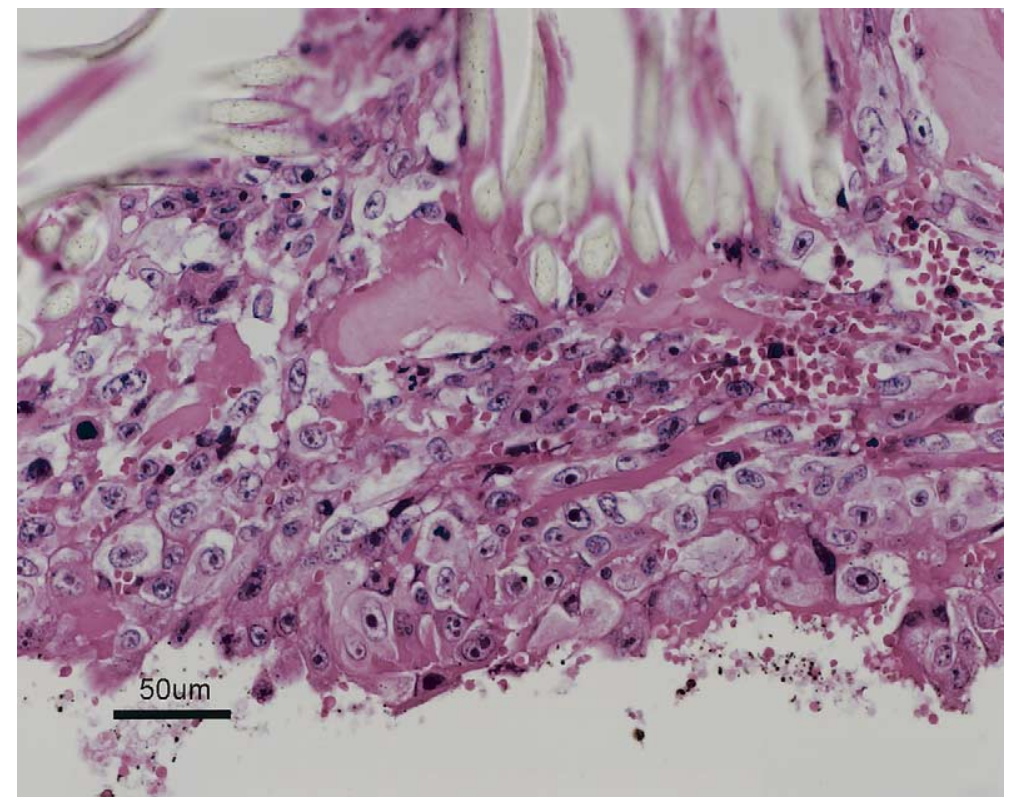

Figure 2. Histologic section showing proliferation of malignant endothelial cells on the Dacron graft fibers (high-power view).

vation. ${ }^{3}$ Sarcomas associated with foreign material commonly have a long latent period of more than a decade.

Primary tumors of the aorta are rare, and the diagnosis is difficult. Most of the reported cases were diagnosed after operation or autopsy. The present case was also diagnosed first to be angiosarcoma with specimens of brain tumors. CT scanning supplemented with angiography helps to delineate masses , and magnetic resonance imaging can define the extent of the invasion and might allow the histogenetic classification. ${ }^{12}$

The presented patient had a previous CT tomography 5 years ago. There was an expansion of the low-density area at the aortic root surrounding the graft compared with the recent scan retrospectively. Hematoma or tumorous mass had expanded in the aneurysmal sac around the aortic root for the last 5 years. 
The prognosis of angiosarcoma depends on the site of origin and on the tumor size but generally is grave. ${ }^{13}$ The origin of the angiosarcoma could not be diagnosed antemortem, but this is the first cardiac angiosarcoma in association with a Dacron graft in the aortic root.

\section{References}

1. Oppenheimer BS, Oppenheimer ET, Stout AP, et al. The latent period in carcinogenesis by plastics in rats and its relation to the presarcomatous stage. Cancer. 1958;11:204.

2. Jennings TA, Peterson L, Axiotis CA. Angiosarcoma associated with foreign body material. Cancer. 1988;62:2436-44.

3. Ben-Izhak O, Vlodavsky E, Ofer A. Epithelioid angiosarcoma associated with a Dacron vascular graft. Am J Surg Pathol. 1999;23(11):1418-22.

4. Fyfe BS, Quintana CS, Kaneko M. Aortic sarcoma four years after Dacron graft insertion. Ann Thorac Surg. 1994;58:1752-4.

5. Weiss WM, Riles TS, Gouge TH, et al. Angiosarcoma at the site of a
Dacron vascular prosthesis: a case report and literature review. $J$ Vasc Surg. 1991;14:87-91.

6. Fehrenbacher JW, Bowers W, Strate R. Angiosarcoma of the aorta associated with a Dacron graft. Ann Thorac Surg. 1981;32(3):297301.

7. De Young BR, Frierson HF Jr, Ly MN, Smith D, Swanson PE. CD31 immunoreactivity in carcinomas and mesotheliomas. Am J Clin Pathol. 1998;110:374-7.

8. Weiss SW, Goldblum JR. Malignant vascular tumors. In: Enzinger and Weiss's soft tissue tumors. 4th ed. Mosby-Harcourt: Philadelphia; 2001. p. 539-69

9. Byers RJ, McMahon RFT, Freemont AJ, et al. Epithelioid angiosarcoma arising in an arteriovenous fistula. Histopathology. 1992;21:87.

10. Keane MM, Carney DN. Angiosarcoma arising from a defunctionalized arteriovenous fistula. J Urol. 1993;149:364.

11. Enzinger FM, Weiss SW. Soft tissue tumors. 3rd ed. St Louis: Mosby; 1995, p. 641-3.

12. Casha AR, Davidson LA. Familial angiosarcoma of the heart. J Thorac Cardiovasc Surg. 2002;124:392-4.

13. Anderson's pathology. 9th ed. Vol. 1. St Louis: Mosby.

\title{
Thymolipoma with high production of carbohydrate antigen 19-9
}

\author{
Shinichi Maekawa, MD, ${ }^{a}$ Kan Okabayashi, MD, ${ }^{\text {a }}$ Masafumi Hiratsuka, MD, ${ }^{a}$ Masakatsu Hamada, MD, ${ }^{b}$ and \\ Takayuki Shirakusa, MD, ${ }^{\mathrm{c}}$ Fukuoka, Japan
}

\section{Clinical Summary}

During routine examination at school, a 16-year-old girl displayed an abnormal mass shadow on chest radiography and abnormal electrocardiographic results, indicating incomplete right bundlebranch block. The patient was referred to us for further evaluation. Chest radiography revealed a large mass in the mid-lower mediastinum that silhouetted bilateral heart borders and conformed to the shape of the heart, simulating cardiomegaly (Figure 1). Physical examination revealed no abnormalities. Laboratory data were within normal ranges, except for an incidental finding of increased serum carbohydrate antigen 19-9 (CA19-9) levels at $102.44 \mathrm{U} / \mathrm{mL}$ (normal, $<37.0 \mathrm{U} / \mathrm{mL}$ ). Computed tomography (CT) of the chest identified a massive heterogeneous mass with fat attenuation mingled with soft tissue extending widely into the bilateral inferior hemithoraces (Figure 2). Magnetic resonance imaging (MRI) of the chest displayed whorls of signal hyperintensity intermixed with areas of intermediate intensity on T2-weighted imaging (Figure 3).

From the Department of Thoracic Surgery, ${ }^{a}$ National Fukuoka-Higashi Hospital, Fukuoka, Japan; the Department of Cardiovascular Surgery, Wajiro Hospital, Fukuoka, Japan; and The Second Department of Surgery, Fukuoka University, School of Medicine, Fukuoka, Japan.

Received for publication Dec 10, 2003; accepted for publication Jan 7, 2004.

Address for reprints: Shinichi Maekawa, MD, 1-1-1, Chidori, Koga-City, Fukuoka 811-3195, Japan (E-mail: maekawas@ fukuokae2.hosp.go.jp).

J Thorac Cardiovasc Surg 2004;127:1845-7

$0022-5223 / \$ 30.00$

Copyright $\odot 2004$ by The American Association for Thoracic Surgery

doi:10.1016/j.jtcvs.2004.01.022

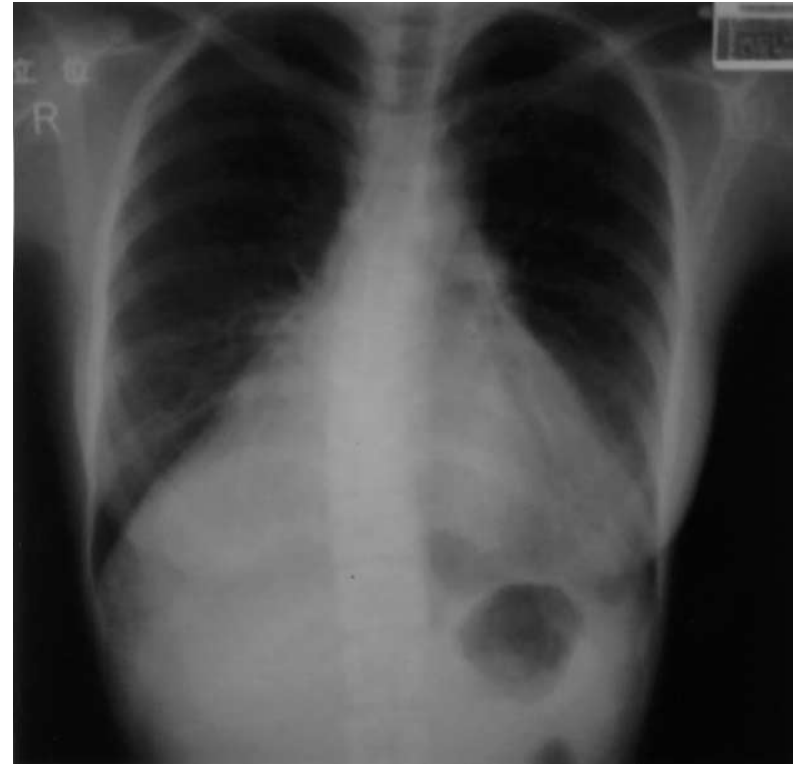

Figure 1. Chest radiography showing a large mediastinal mass extending into both the right and left hemithoraces.

Finally, CT-guided fine-needle aspiration biopsy revealed thymolipoma.

The tumor was approached through a median sternotomy. The mass was spread expansively anterior to the pericardium, stretching both phrenic nerves posteriorly and extending inferiorly into both hemithoraces. Both lobes of the tumor were resected en bloc. 